\title{
CORRIGENDUM
}

\section{Extended survival and reduced risk of AML progression in erythroid-responsive lenalidomide-treated patients with lower-risk del(5q) MDS}

AF List, JM Bennett, MA Sekeres, B Skikne, T Fu, JM Shammo, SD Nimer, RD Knight, A Giagounidis on behalf of the MDS-003 Study Investigators

Correction to: Leukemia (2014) 28, 1033-1040; doi:10.1038/leu. 2013.305

Since the publication of this article it has been noted that there was an omission in the listing of conflict of interest. JM Bennett was listed as having no conflict of interest; however, the authors would like to correct this to read:
'JMB is a consultant for and has received honoraria and contract monies as a consulting hematomorphologist from the Celgene Corporation'.

The authors apologise for any inconvenience caused by this error. 